\title{
PARTIAL INSANITY AND OTHER MITIGATING PSYCHOLOGICAL CIRCUMSTANCES UNDER ALBANIAN CRIMINAL LAW ${ }^{1}$
}

\section{Dorina HOXHA}

Prof. Asoc., Head of the Department of Criminal Law, Faculty of Law, University of Tirana

E-mail: dorina.hoxha@fdut.edu.al

\section{Kreshnik MYFTARI}

Lecturer of Crimal Law, Department of Criminal Law, Faculty of Law, University of Tirana

E-mail: kreshnik.myftari@fdut.edu.al

\begin{abstract}
Albanian criminal legislation gives a special place to the mitigating circumstances of a psychological nature applied to the perpetrators of criminal offenses. In the Albanian doctrine, the psychological state is considered part of the subjective component which in itself has, in essence, the existence or not of responsibility and the extent of the perpetrator's guilt. Referring to its formulation, the article of the Criminal Code providing for the mitigating circumstances mentions only one circumstance of a psychological character, psychiatric distress. The same relevance and legal treatment as the mitigating circumstances can be encountered in other institutes, such as the reduction of mental balance or the commission of a criminal offense in a state of intoxication. Thus, this manuscript analyzes the mitigating circumstances provided by the Albanian criminal legislation through the method of comparison while identifying the shortcomings in cases when these circumstances constitute at the same time general institutes of criminal law.
\end{abstract}

Keywords: Albanian criminal law, mitigating circumstances, partial insanity, psychiatric distress, inebriation, narcotic intoxication, emotional state

\footnotetext{
${ }^{1}$ All non English material used in this manuscript for academic purposes only are translated from Dr. Kreshnik Myftari
} 


\section{Partial Insanity and Other Mitigating Psychological Circumstances Under Albanian Criminal Law}

Most of the Albanian legislation is inspired and formulated according to the Italian model. The Albanian Criminal Code has borrowed almost all the institutes of a general nature and many concrete figures of criminal offenses from the Italian code. Although almost identical in institutes and formulations, regarding the institute of mitigating circumstances, we encounter some essential differences in the two codes.

In addition to the mental disorder that completely disrupts the mental balance and consequently makes the person irresponsible before the law, the Criminal Code, in article 17, point 2, provides for a partial reduction of mental balance, which comes as a result of a mental disorder. Even though the person is considered responsible and the punishment is applied to him according to the law, such a mental disorder is considered by the court in determining the measure of punishment referring to it as a mitigating circumstance.

The above approach, according to most, represents a solution inspired by the context of social values, rather than by criminological and scientific opinions. The institute of reduction of mental balance was reaffirmed by the Criminal Code of 1995, though not without objections, in order to resolve the cases of those subjects who, although not completely deprived of the ability to understand actions and desire the consequences, do not have psychic normalcy.

Decreased mental balance, otherwise called half-responsibility or diminished responsibility has been the topic of discussion by lawyers and psychiatrists. In the opinion of some, the decline of mental balance opens the doors of madness and from there to a dead end. On the other hand, there are those who think that diminished responsibility is not only to be pursued but is necessary to understand complete irresponsibility. While in the middle stand persons in favor of the concept of irresponsibility, but against the concept of reduced responsibility. Currently the debate focuses on proposals for a reduced responsibility or for a reduced ability.

At the same time other circumstances such as psychiatric distress, inebriation and use of narcotics, all provided for by the criminal legislation as mitigating circumstances of a psychological nature, have the same theoretical problems in interpretation and practice when it comes to their application in court.

\section{Partial Reduction of Mental Balance in Criminal Law}

Although the legislature has not listed the partial reduction of mental balance provided by Article 17, point 2 of the Criminal Code in the mitigating circumstances provided by Article 48, it is essentially considered as such, based on the grammatical and logical interpretation given to both norms and general spirit of the Code. 
The partial reduction of mental balance is encountered in those cases when the ability to understand the actions and to wish the consequences is reduced, according to the provision of Article 17, point 2 of the Criminal Code:

"The person who at the time of the commission of the criminal offense suffered from a mental or neuropsychic disturbance, which has reduced his mental balance to fully understand and control his actions or omissions, is liable, but this circumstance is taken into account by the court in determining the extent and type of punishment."

The fact that this circumstance is taken into account by the court in determining the measure and type of punishment, gives this institute the legal status of a mitigating circumstance.

The partial reduction of mental balance is one of the most controversial moments in both criminal law and forensic psychiatry, as the problems related to the clinical character such as ascertainment and legal treatment are not clearly distinguished. (Prosecution Office Korce v. Adri, 2013)

Initially, the terms "reduction of mental balance" and "half responsibility" were considered a legal fabrication, recognizing that a subject is either ill or healthy and cannot be half-sick and half-healthy. (Antolisei, 1991) However, today most criminologists and psychiatrists agree that although it is very difficult to ascertain in practice, the partial reduction of mental balance has a scientific basis as there are subjects who possess the ability to understand actions and desire the consequences, but due to diseases or neuroses do not have this ability at a normal level. (Fiandaca \& Musco, 2014)

In order to avoid that any form of neurosis, a character anomaly being considered as a decrease in mental balance, paragraph 2 of Article 17 requires that the ability to understand actions and to desire the advent of consequences be significantly reduced, since it is a matter of serious pathological condition. (Vehbiu \& Shtino, 1986)

Since the law places emphasis on the "degree" rather than the "extent" of mental disorder, in the case of systematic delusions, criminal liability is completely ruled out, while in mental disorders, which involve the entire brain, criminal liability may be reduced. (Prosecution Office Durres v. Gjoka, 2014) It is the duty of psychiatry and not of jurisprudence to ascertain a complete or partial reduction of mental balance. (Finkel, 1988) General indicators of mental illness have no value in this view, leading to the need for case-by-case verification based on the nature of the person and psychiatric indicators. Particularly difficult is the assessment of some types of psychopathic deviations, in which the character of the disorder is not always distinguished and which are of little importance in the criminal sense. Only in some more severe forms can a partial decrease in mental balance be observed. In the judgment of psychopathic personalities, among other things, importance is given to the nature and manner of execution of the criminal offense, in order to find the connection between the psychopathic disorder and the determination to commit the criminal act. (Fornari, 1997)

Jurisprudence in general, while acknowledging that psychoses completely or partially exclude the ability to understand actions and desire the 
consequences, rules out the existence of criminal liability in the case of neuroses, sentimental disorders and any anomalies of this kind, not direct consequence of a pathological condition clinically proven. (Prosecution Office Vlore v. Vasili (Saliaj), 2016)

The partial reduction of mental balance poses the problem of determining to what extent the anomaly may affect guilt, to what extent other components of the subjective element such as premeditation, intentions and motives may coincide with the partial reduction of mental balance. (Delpino, 2010) The doctrine denies that premeditation can impose criminal liability on a subject who is psychologically abnormal, since although the intensity and persistence of criminal thought presuppose full criminal responsibility, it is objectively impossible to determine whether this premeditation is a consequence of the subject's abnormal condition or not. (Delpino, 2010)

It is generally accepted that the partial reduction of mental balance coincides with external provocations. (Kambovski, 2010) Anger is an emotional state that is not part of the causes of partial loss of balance, but the person suffering from this disorder may experience the injustices of the actions of others to the extent that there is an immediate reaction to the ongoing anger, an action, which in this case, is considered legitimate. We will deal with emotional and passionate disorders next.

Unlike the Albanian Criminal Code, the Italian code provides that the court apply the medical measures provided by law against a person with reduced mental balance such that he poses a social danger. (Marinuci \& Dolcini, 2012) Such a provision is not made in the Albanian criminal norms. The appointment of a medical measure for this category of subjects according to the Albanian criminal legislation is at the discretion of the psychiatrist making the decision. In this case, medical measures are applied after the criminal sentence has been served and consists mainly of compulsory outpatient treatment. However, the judge, considering the special conditions of the convict's mental state, may apply the medical measure before the execution of the sentence. (Strazimiri v. Albania, 2010)

\section{The Difference Between a Complete Breakdown and a Partial Decrease in Mental Balance}

As the jurisprudence points out, there is an exclusively quantitative difference between complete disruption and partial reduction of the mental balance in accordance with the degree of the effect of subject's mental disorder. More precisely, in a complete breakdown of mental balance, to the extent that it completely excludes the ability to understand actions and to desire the consequences, while in a partial reduction the degree of the disorder, no such exclusion of the ability to understand actions and desire the advent of consequences is allowed, but the disorder causes just the limitation of mental ability. (Prosecution Office Tirana v. Qiqi , 2014) 
The legal doctrine explains that the partial reduction of mental balance should not be understood as an abnormality affecting a certain part of the brain, in other words as a partial disorder of the brain, but it affects the whole brain, only with a lower intensity compared to the overall decrease in mental balance. (Vehbiu \& Shtino, 1986) In the case of the subject, who suffers from a disorder that has caused a partial decrease in mental balance, guilt as a psychic attitude of the person during and after the commission of the criminal offense is considered lower. (Muci, 2007) As for the subject acting with a lower degree of guilt, although caused by the partial reduction of mental balance, in jurisprudence there remains no doubt that there must be a compatibility between the reduction of balance and intent. (Elezi, Kacupi, \& Haxhia) So, there is no objection that in the case of accepting the reduction of mental balance, it must be proved that the criminal offense was committed intentionally, with conscience and will, albeit diminished. (Prosecution Office Korce v. Gora \& Shehu, 2017)

When it comes to a disorder that has caused a partial decrease in mental balance, one that differs only quantitatively from the disorder that has led to a complete breakdown of mental balance, in the opinion of some jurists, that only the mental disorder that has a psychiatric-legal character matters depending on a serious pathological condition that leads to the degradation of the intellectual and volitional sphere of the subject. (Hoxha, Kacupi, \& Haxhia, 2018) In this view, a "clinically definable pathological" condition is required at the limits of partial reduction of mental balance. Consequently, character disorders and passionate emotional states do not carry a pathological burden to such an extent as to significantly reduce criminal liability.

As in the case of complete mental imbalance, in the case of a decrease of mental balance, there are used three main systems: (Zappa \& Alberto)

a. Psychopathological-legal method; Mental disorders are assessed according to the impact they have on the ability to understand actions and omissions and to desire the consequences. This is the method used of Italy and many other countries such as Germany, Denmark, the Netherlands, Austria, Ireland, France, Greece and United Kingdom.

b. Psychopathological method; This method sanctions impunity for diseaseaffected subjects without assessing the impact on the ability to understand actions and omissions and to desire the consequences. This method is used in Nordic countries such as Norway and Sweden.

c. Legal method; This method does not consider psychological problems, but brings the need to assess the ability to understand at the time of commission of the act "tempus commissi delicti".

The partial reduction of mental balance in some legislations is a moment considered inseparable from irresponsibility, but in others it stands as an optional basis for a lighter sentence. Thus, some legislations authorize the courts to soften the sentence indefinitely for the perpetrator of the criminal offense with a reduced mental capacity, while other legislations provide for the commutation of the sentence to a certain extent, which means a lighter sentence, but within the limits of the rules for mitigation of punishments provided by law. 
(Faulk, 1988) Under Albanian legislation, reduced mental capacity is the optional basis for mitigation of sentence. (General Prosecution Office v. Zyka, 2012) The latest theories of forensic jurists and psychiatrists consider the distinction between the complete and partial reduction of mental balance to be arbitrary. Often such a finding is dictated by the possibilities and circumstances of the facts, as in the case of a partial reduction of mental balance, although responsible, the person receives a milder sentence due to the mitigating circumstances in which he finds himself. (Perkins, 1934)

\section{The Difference Between Semi-Responsibility due to Mental State and Profound Psychiatric Distress}

A mitigating circumstance of a psychological nature provided by the Criminal Code is the profound psychiatric distress. This circumstance, at first sight creates, the impression of resemblance to the partial reduction of mental balance or semi-responsibility provided by article 17, paragraph 2 of the Criminal Code, but legally the two institutes are completely different for the reasons that will be explained below. However, there are cases when the person has committed the crime not under the influence of a mental illness, but under the influence of some external harassment, which has exerted a great influence on the psyche by inhibiting consciousness and self-control, or otherwise called physiological affect. (Elezi, 2014)

The profound psychiatric distress as a physiological affect weakens the reason being influenced by external harassment, such as insults and swearing. In this case these external factors influence self-control and consequently cause the direct reaction to these unjust actions. Nevertheless, physiological affect, as opposed to irresponsibility, does not disturb mental balance to the extent that the person is unable to control his actions and omissions. The physiological affect simply reduces the consciousness of the individual, leading to the consequence that at the moment of committing the criminal offense, he acts with direct intent, as a form of guilt. Unlike irresponsibility due to mental state, which is known as the pathological affect, in which the person acts under the effect of the disease, where the latter is the reason for the crime, profound psychiatric distress makes the person accountable before the law. However, the Albanian Criminal Code, article 48, letter (b), provides for a mitigating circumstance by significantly reducing the sentence limits in cases where this affect is found.

Profound psychiatric distress should be instantaneous, being evident immediately after the unjust action. It will not be considered as such if sufficient time has elapsed between the external harassment and the reaction of the person, an interval in which the person could judge calmly and take legal action and not act individually by committing a criminal offense. Time is an element that makes profound psychiatric distress similar to the irresponsibility due to mental state. (Hoxha, Kacupi, \& Haxhia, 2018) 
Every unjust action affects the psyche of the person and consequently shocks him, but not every distress is considered a profound psychiatric distress. (Prosecution Office Shkoder v. Leci, 2011) Just like the physiological affect, the pathological affect as well must be immediate, the mental disorder must have existed at the time of the commission of the criminal offense. In both of the above cases, the victim unjustly causes, through serious insult or violence, the state of the profound psychiatric distress of the defendant, who, at that moment, commits his criminal act. The difference between the above criminal institutes lies in the level of physiological affect and consequently, the level of consciousness and the ability to understand, think and control actions. (Muci, 2007; Elezi, Kacupi, \& Haxhia, 2007) Instantaneous profound psychiatric distress is otherwise called physiological affect, an extremely strong, instantaneous emotional state, which leads to a decrease in the ability to understand, think and control actions. (Prosecution Office Tirana v. Abazi \& Citaku, 2015)

The special part of the Albanian Criminal Code provides for two special norms that contain in their definition the phrase "committed in a state of instantaneous profound psychiatric distress". One of the criminal offenses is directed against life, "murder committed in a state of profound psychiatric distress", article 82 of Albanian Criminal Code, and the other is directed against health, "serious injury in a state of profound psychiatric distress", article 88/a of Albanian Criminal Code. (Prosecution Office Kukes v. Kerxhalliu, 2015; Prosecution Office Tropoja v. Osmanaj, 2018) Precisely the definition of the institute of mitigating circumstance and the use of this phrase in two special criminal offenses has led to misinterpretations in the Albanian judicial practice. There are jurists who think that instantaneous profound psychiatric distress and psychiatric distress are two different legal concepts, based on the intensity and extent of unjust action. In our view this interpretation is wrong. Profound psychiatric distress in both, mitigating circumstances and the two special norms is one and the same and is based on the infliction of the physiological affect. (Prosecution Office Tropoja v. Ukcamaj, 2011) The lack of physiological affect does not make the action performed with a weakened consciousness and self-control but would make it an action performed in the conditions of irascibility and it is precisely because of this condition that the institute of psychiatric distress is misinterpreted as a mitigating circumstance. Another reason for these misinterpretations is the use of the term "profound" in the two special criminal offenses and simply "psychiatric distress" in the institute of mitigating circumstances, article 48, point (b). This problem has to do with the syntax used in the legislation, while it should have used the same formulation as long as it has the same meaning.

In the essence of the profound psychiatric distress provided for in the special norms such as "murder committed in a state of profound psychiatric distress" and "serious injury in a state of profound psychiatric distress", is the unjust action based on violence or insult of the aggressor or victim. (Prosecution Office Shkoder v. Terolli, 2017; Prosecution Office Shkoder v. Ramja, 2011) These unjust actions are not foreseen in the institute of psychiatric 
distress provided as a mitigating circumstance by the general part of the Criminal Code. It is still debated in practice whether there can exist the profound psychiatric distress as a mitigating circumstance in the qualifications of the murders, especially in the murder committed against two or more persons provided by article 79 , point (dh), the murder of public officials, provided by article 79 / a, the murder of state police officers, provided by article 79 / b and the murder due to family relations, provided by article 79 / c. The Criminal Chamber of the High Court has ruled on this issue. (Prosecution Office Tirana v. Lataj, 2017) Regarding the instantaneous profound psychiatric distress, we must emphasize that according to the Criminal Code, there is only one criterion, the legal one. In other words, for the assessment of profound psychiatric distress, the Criminal Code does not necessarily require the perpetrator to undergo a psychiatric examination. In many cases it is accepted a priori by the court, when clearly and indisputably the circumstances of the fact show that the person who committed the criminal offense acted precisely in the state of this physiological affect. So, unlike the institute of partial reduction of mental balance or semi-responsibility which according to the Albanian criminal legal doctrine has basically two criteria for identification, legal and medical, the institute of instantaneous psychiatric distress, refers for identification only to the legal criterion, having in essence the existence of a psychic pathology in the first case and the unjust action for the second institute.

However, referring to the case law, especially of the Court of Appeals, there are cases when the help of psychiatric experts is required to determine the instantaneous profound psychiatric distress. These cases of judicial practice have been encountered only when the suspect has been detained after a relatively long time after committing the criminal offense and the opinion of the expert is the only means to prove the existence or not of a physiological affect in the past.

\section{Inebriation and Use of Narcotic and Psychotropic Substances. Their Impact on the Ability to Understand Actions and to Desire the Advent of Consequences.}

The use of alcohol and narcotics and psychotropic substances undoubtedly has an impact on the psychological state of the perpetrator of the criminal offense. The commission of a criminal offense while inebriated or under the influence of narcotic and psychotropic substances has an effect on the psyche of the perpetrator at the time of the commission of the criminal offense. Depending on the case or intent, the legislature has given this institute the value of mitigating or aggravating circumstance. Inebriation, just like the partial reduction of mental balance, is not provided for in the article on mitigating circumstances, but the legislature has given this institute the same value, that is, the mitigating circumstance in all cases when it is accidental.

In the opinion of some jurists, even inebriation causes the muchdiscussed morbid or crepuscular condition, a condition in which the subject 
lacks the ability, lacks desire, and also reason. Whether this condition occurs only in persons who act in conditions of pathological inebriation or other types of intoxication, with the exception of premeditated inebriation, is an issue that is still under discussion among lawyers.

As in the criminal codes of other countries, the Albanian Criminal Code, in article 18, provides for the commission of a criminal offense while inebriated.

"The person who committed the criminal offense while inebriated is not excluded from responsibility.

When inebriation is caused in occasional circumstances and has brought about a decrease in mental balance, this circumstance is taken into account to mitigate the punishment against him.

When inebriation is intentional in order to commit the offense, this circumstance is taken into account for the aggravation of the sentence.

The above rules also apply when the criminal offense is committed under the influence of narcotics or other simulants."

In interpreting this article, the Albanian Criminal Code does not exempt from criminal liability a person who commits a criminal offense under the conditions of inebriation. The second paragraph stipulates that in case the inebriation is accidental, this circumstance is taken into account by the court in the execution of the sentence, it is considered as a mitigating circumstance because it has brought about the reduction of mental balance. Whereas if it was committed intentionally it is taken into account in the form of aggravating circumstance. To understand inebriation as accurately as possible we must return once again to the concept of the ability to understand actions and to desire the advent of consequences. Inebriation affects this ability in the same way as the decrease in mental balance due to mental or neuropsychic disorder.

The Albanian Criminal Code, unlike the criminal codes of other countries, is out of date referring the relation between inebriation and intoxication with the complete exeption from criminal liability, its new forms and the cases when it does not only bring a decrease in mental balance, but its disruption as a whole. Casual inebriation represents an extraordinary hypothesis compared to the voluntary inebriation which derives from an unpredictable and incalculable case. (Dolcini \& Marinuci, 2006) In order for the inebriation to be accidental, the person must fall into its conditions without guilt, so he must not have the will to get drunk. (Antolisei, 1991) The same principle applies to cases where the person is in medical therapy (with medication) which affects the ability to understand the actions and to wish the consequences. (Fiandaca \& Musco, 2014) The concept of inebriation enters into the concept of inebriation without guilt even when the rate of the ability to understand actions and desire consequences occurs due to an error in the quantity or quality of alcohol. (Vehbiu \& Shtino, 1986) In order for the alcohol inebriation to lead to a disorder of the intellectual and volitional process, it must reach a high rate compared to a psycho-physical pathological condition of a transient nature. Forensic science considers inebriation and use of narcotics as a genuine pathological disorder, due to the addiction that these substances often create. In the Italian Criminal 
Code, the change of psycho-physical abilities shows how a similar situation provided in the case of irresponsibility, completely removes the ability to understand actions and to desire the consequences or reduces this ability in the same way as in the case of decrease of the mental balance due to a psychic disorder. (Delpino, 2010) In this case the assessment of the ability to understand actions and to desire the advent of consequences is examined on a case-by-case basis, considering the concrete objective and subjective circumstances, in addition to those included in the legal concept of inebriation. The concept of inebriation in itself does not contain a hypothesis of irresponsibility and as such should be distinct from mental disorder.

Therefore, it can also be found in people who suffer from a complete or partial decrease in mental balance. In the case when the same person at the same time is affected by a complete or partial disorder of mental balance, and is in a condition of complete inebriation without guilt, the theoretically applies the principle according to which the person should not be held criminally liable. In these cases, as in the case of persons with mental disorders, medical measures of hospitalization in a psychiatric hospital must be applied in accordance with the Criminal Code. (Vehbiu \& Shtino, 1986) Although inebriation does not equalize with the irresponsibility due to mental state, Albanian judicial practice equates inebriation to irresponsibility in case it has completely affected the ability to understand and control actions, and therefore the person is exempted from criminal liability. The condition when the person is excluded from liability due to inebriation is the pathological one.

Pathological inebriation is also a frequently discussed topic in Albanian criminal law. For example, in some criminal law texts, pathological inebriation is seen as an exception to the general rule. The person loses consciousness and as such is unable to understand his behavior. Other authors equate it completely to irresponsibility, whether pathological inebriation or the influence of strong doses of narcotics, under the effect of which the person completely loses control. Unlike casual inebriation, which reduces criminal liability, the pathological situation is completely different, because these persons not only cannot be criminally punished, but the Criminal Code does not provide for the application of any coercive measure against them, such as the case of psychiatric hospitalization or compulsory outpatient treatment, applied to irresponsible persons. In this case, it is reasoned that the criminal offense should not be psychologically attributed to the person who consequently does not pose a social danger. In a limited number of subjects, drinking alcohol in small or moderate amounts can lead to an acute condition characterized by severe psychic and behavioral changes. This episode occurs unexpectedly, within a few minutes of the person drinking alcohol and lasts for several hours. In this case the person may have psychic hallucinations, illusions or temporary mental confusion. (Faulk, 1988) Usually pathological inebriation ends with a prolonged and very deep sleep from which the subject when waking up remembers little or nothing of what happened. Thus, in the case of the so-called pathological inebriation, as a consequence of the abnormal and unpredictable 
effects of alcohol the principle should be applied according to which inebriation should be accidental and the person unaware that he is affected by it.

Paragraph 3 of article 18 of the Criminal Code considers a fully responsible person as one who is in a state of voluntary inebriation even if he or she lacks the ability to understand actions and to desire the consequences. A more severe treatment of inebriation than the occasional ones is done in the case when it is premeditated. In this view the person will not only be criminally liable for the offense committed, but it will be considered committed intentionally and will be taken as an aggravating circumstance in setting the sentence.

Referring to the state of voluntary inebriation and irresponsibility due to mental state, according to jurisprudence, epileptic disorders or other manifestations of mental state, can also occur in the case of drinking a small amount of alcohol. In these cases, the judge must seek psychiatric expertise to ascertain irresponsibility due to the mental state, as well as to consider the continuing character of inebriation rather than the state of inebriation itself.

The legislature treats premeditated inebriation more harshly than casual inebriation or alcoholism, a circumstance which is taken into account for aggravating the sentence. The Italian Criminal Code, unlike the Albanian code, provides for continuous inebriation. In case this kind of inebriation is found, it is considered by the court as a mitigating circumstance in setting the sentence. (Dolcini \& Marinuci , 2006) In the interpretation of criminal law, the use of alcoholic beverages permanently is considered continuous inebriation. This interpretation, the continuation of the use of alcohol, also applies to cases of drug and psychotropic substance use. Two conceptual elements stand out in continuous inebriation: 1) the person must constantly consume alcoholic beverages, and 2) his inebriation must be permanent. There is a difference in the case of the use of narcotics and psychotropic substances, as here the two elements are no longer needed. The only element which is needed in this case is the first one, the person must be under the effect of these substances all the time. (Fiandaca \& Musco, 2014) One problem that arises in practice is the difference between permanent and chronic inebriation. The difference lies in the fact that in continuous inebriation the subject still retains control of his habit and can abandon it by force of will while restoring normalcy. (Shtino \& Lala, 2011) In chronic inebriation the subject cannot undertake any effective behavior in relation to his condition.

Jurisprudence seems to have no doubts regarding the elements on the basis of which a distinction is made between permanent and chronic intoxication, whether from alcohol or narcotic substances. (Prosecution Office Fier v. Shehaj, 2014) In both cases the practice has confirmed that intoxication that is a consequence of alcohol or narcotics, have an impact on the nervous system and exclude the person from criminal responsibility when they cause permanent pathological disorders. (Mantovani, 2001)

Recognition of ordinary inebriation or intoxication by narcotic and psychotropic substances not only leads to an increase of the punishment as an aggravating circumstance, but in the legislation of many countries it also 
determines the social danger of the subject by placing him in security measures such as under hospital treatment or probation. According to jurisprudence, a person is chronically inebriated when, because of its indelible character and impossibility of healing, provokes stable pathological conditions the same as those caused by a mental disorder. (Prosecution Office Pogradec v. Piperi, 2013)

In conclusion we can say that not all degrees of inebriation or intoxication from narcotic substances, which constitute a purely psychic addiction to alcohol or drugs, or chronic addiction to them, can produce a mental disorder of the subject important in the criminal sense. From this point of view, there is a disorder of the will and consequently the ability to understand actions and to wish for the consequences in abstinence crises. In criminal law, the right concept of inebriation and intoxication from narcotic and psychotropic substances does not consist in the consequences that arise from the simple use but from the abuse of alcohol or the substances in question. (Prosecution Office Fier v. Xhulaj, 2016)

It is important for lawyers and psychiatric experts to distinguish between occasional and intentional intoxication. Unfortunately, science has not developed any method to achieve this result, therefore this presents difficulties in practice. In cases of a criminal offense being committed by a person in state of intoxication, intuition is the only means of distinguishing whether the perpetrator has been intoxicated accidentally or intentionally. What should be required from the drunk person who has committed a criminal offense, especially from the prosecuting authority, are the motives for committing the offense in question, in order to understand whether the occurrence of socially dangerous and illegal consequences was desired, even premeditated by the person, or if they have come about by accident. The same rules as for inebriation apply when the offense is committed under the influence of narcotics or other psychotropic substances.

Another important issue has to do with the choice of criminal policies set by the legislature adhering to the need for prevention. As for those subjects who break the law in conditions of voluntary inebriation or under the influence of narcotics, despite the obvious lack of ability to understand the actions and to desire the consequences, they are not exempted from criminal responsibility, on the contrary aggravating circumstances are applied to them. Even in this case, what has set the legislature in motion is the need to prevent these behaviors, therefore it has adopted these solutions, in order to achieve the most appropriate objectives. Some have criticized this instrument, considering it a form of objective responsibility, in contrast to the principle of culpability. 
Partial insanity and other mitigating psychological...

\section{Emotional and Passionate State and Exclusion From the Sphere of Irresponsibility}

In the criminal codifications of many European countries the emotional and passionate state constitutes a mitigating circumstance due to the psychological and spiritual nature. Unlike the Albanian Criminal Code, article 90 of the Italian Criminal Code immediately after irresponsibility due to mental state and partial reduction of mental balance, provides for emotional and passionate state, which does not exclude the subject from criminal responsibility. According to the legal interpretation, the person will be criminally responsible during the emotional and passionate state, as long as these do not constitute a mental disorder and have no pathological character. For example, jealousy as a passionate state does not affect the development of the ability to understand actions and to desire the consequences. (Dolcini \& Marinuci, 2006) The meaning of emotional and passionate state seems to be in line with the definition of irresponsibility due to the mental state focusing on the intellectual and volitional moment. Other factors outside the intellectual and volitional sphere are categorically not included in the concept of irresponsibility. (Hoxha, Kacupi, \& Haxhia, 2018)

The development of psycho-pathological sciences made it possible for the doctrine to include in the definition of emotional and passionate states of disturbance of consciousness, regardless of the pathological causes. (Shtino, 2003) The emotional and passionate state itself may be a preliminary symptom of a pathological mental disorder, but it always lies within the boundaries of the concept of irresponsibility. Thereby passionate states such as jealousy, anger, and fear can affect the subject's self-control, but can in no way affect the ability to understand and desire the consequences. Part of the doctrine, although recognizing the non-pathological origin of such reactions and the fact that they lead to emotional and passionate states, acknowledges that in certain situations these types of reactions may be presented as manifestations of a real disease. (Shtino, 2003) However, jurisprudence and doctrine have set a limit to the interpretation of the insignificance of emotional and passionate states and their impact on irresponsibility, accepting the complete disruption or partial reduction of mental balance when the emotional and passionate state constitutes an external manifestation of a real mental disorder with pathological character. (Kambovski, 2010)

At the same time, the Criminal Code of Kosovo, although composed according to the Albanian Criminal Code, explicitly provides for mental disorders. Accordingly, mental disorders refer to the state which is presented as damage to the psychic process to the damage of the normal development of the psychic process of the perpetrator, therefore the latter is not able to judge and decide correctly. Mental disorders can be inherited, congenital and acquired over time. They may be disorders inherited from the parents or ancestors of the offender. Congenital mental disorders are those disorders created due to injury, intoxication or disease of the brain or endocrine glands, while time-acquired mental disorders are created during life. Causes of mental disorders can be 
organic and of a psychological-social nature. Inheritance, injuries, lifethreatening diseases, specifically diseases of the brain and endocrine glands are most often presented as causes of organic nature. (Petroviq, 2006) While a cause of psychological-social nature is the spiritual shock which is presented due to the conflict in a social environment, because of unexpected life events which have a dramatic, stressful or other similar character without emphasizing the unjust actions of victims or injured. Given the duration of the existence of spiritual disorders, the Criminal Code of Kosovo divides them into temporary and permanent. Permanent mental disorders refer to mental illnesses that last for a long time, which cannot be cured spontaneously and that despite treatment with modern therapeutic medical methods, remain unhealed. Major mental illnesses include schizophrenia, epilepsy, progressive paralysis, and paranoia. (Vehbiu \& Shtino, 1986)

Temporary spiritual illness means shorter-term (temporary and periodic) mental illness, which can be stopped spontaneously or can be cured through modern medical treatment. These are diseases that create delusions, which can be associated with the phenomena of systemic hallucinations. This group of diseases include various poisonings or intoxication. Temporary spiritual disorders are those diseases which present at unequal time intervals as a delusional state. These diseases are dipsomania (uncontrolled drinking), delirium tremens (insanity of uncontrolled drinking alcohol), hallucinations and alcoholic jealousy, the dark state of patients with epilepsy. (Petroviq, 2006)

Periodic spiritual disorders are those diseases which occur in approximately equal periods of time between which there are free intervals, intervals in which the person is mentally healthy. These diseases include bipolar disorder. Bi-polar can be related in such a way that the intervals of illness and health are combined in the form of manic state - free interval - depressive state, melancholy - free intervals. (Salihu, 2010) The emotional and passionate state and spiritual disorders provided by the Criminal Code of Kosovo, at first sight seem to have an approach to the profound psychiatric distress, provided by the Albanian Criminal Code, but if we make a detailed analysis the commonalities are very few or non-existent. We say this because emotional and passionate states are considered jealousy, anger, and fear influenced or not by an external factor, while the spiritual disorder is presented as spiritual injury or mental illness. The causes of spiritual disorders remain unclear and debatable. Meanwhile, profound psychiatric distress, as a psychological affect is seen as an instantaneous, lightning condition, which affects the self-control and judgment of the subject but is always caused by external factors which are based on the unjust action. Another equally important difference is the fact that the emotional and passionate state does not affect the exclusion or mitigation of criminal responsibility, according to the Italian Criminal Code. Meanwhile, mental disorders and profound psychiatric distress constitute mitigating circumstances, respectively according to the Criminal Code of Kosovo and the Albanian Criminal Code. 
Partial insanity and other mitigating psychological...

\section{Conclusions and Recommendations}

The partial reduction of mental balance is one of the most problematic and controversial moments in both criminal law and forensic psychiatry, as the problems related to the clinical character, ascertainment and legal treatment are not clearly distinguished.

Criminal law bases irresponsibility on two criteria, medical and legal. This division serves to understand the concept as accurately as possible and to make a correct definition of the cases encountered in practice. Specifically, the Albanian Criminal Code does not provide a separation of the two criteria, it simply defines complete and partial irresponsibility as a result of a psychic or neuropsychic disorder.

There are continued debates about the importance of one criterion over another. In the case law of foreign countries, there are numerous decisions that refer to the medical criterion, considering it sufficient to determine irresponsibility. Undoubtedly, the ascertainment of mitigating circumstances of a psychological nature is made by experts appointed by the proceeding body, the court or the prosecutor, but whether these circumstances will be recognized as mitigating ones or not, this will result from the main trial.

In order for the concept of reduction of mental balance to be included in the mitigating circumstances without creating misunderstandings, it is necessary to amend the Criminal Code of the Republic of Albania by adding an article before article 17, which provides for the ability to understand actions and omissions and to wish for consequences. Only by having an exhaustive definition of the ability to understand will we be able to apply the mitigating circumstances of a psychological nature appropriately.

At the same time there is a need for reformulation of the second paragraph of article 17, the reduction of mental balance or otherwise of semiresponsibility. The concept of semi-responsibility is almost the same as that of irresponsibility. In semi-responsible individuals, the essence lies in affecting the ability without compromising it completely. In this second paragraph of the article the ability to understand is the main element and at the same time it constitutes the legal criterion. Like the first paragraph, this one is quite limited in terms of interpretation. Only mental disorders are required to reduce mental balance, and the Criminal Code leaves no room for reliance on various factors, which would partially impair the ability to understand. With the term various factors we refer to personality disorders, emotional disorders and obsessions that stand between the concepts of semi-irresponsibility and psychiatric distress, for which even jurists and forensic psychiatrists are unclear and at the same time unable to give a definitive classification.

Inebriation and use of narcotics, in the doctrine of criminal law are known as behaviors that impair the ability to understand or partially reduce this ability. The Albanian Criminal Code provides for inebriation and use of narcotics as mitigating circumstances and not as a reason for exclusion from criminal liability, while criminal codes of other countries recognize these circumstances as conditions for exclusion from liability and often equate them 
with mental disorder. The provision of pathological inebriation constitutes a special provision in the European criminal codes, so we believe that the time has come for article 18 of the Albanian Criminal Code to be amended. It should be directly related to the ability to understand, to provide for different types of inebriation and to exclude from criminal liability persons who commit the offense under conditions of pathological inebriation. In this regard, the Criminal Code needs a detailed definition of pathological inebriation. Currently our criminal law does not recognize this type of circumstance, leading to confusion between experts and courts. In case the provision of the ability to understand would be incorporated in the Criminal Code, it would be simpler to state a definition of pathological inebriation and also a simpler interpretation of the law in practice.

However, the relationship between complete or persistent inebriation with the ability to understand and with the action committed has a different approach in civil law. If the legal action committed by a drunk person in the conditions of a complete inebriation is contested in court, it is most likely for the court to consider the action invalid, because at the time it was committed, the person, as a result of inebriation, did not have the ability to understand, did not have the will or consciousness. It is different in criminal law where the action is no longer a legal action but a criminal action, which brings a certain consequence, provided by law as a criminal offense. In this case the criminal law acts differently by acknowledging that the criminal act, although committed in conditions of inebriation, manifests will and conscience, in other words the person performs the criminal act with full ability. Consequently, the person is not excluded from criminal responsibility, he is considered responsible, but this circumstance serves as a mitigating one in giving the sentence. We think that this is the case when law provisions have two standards, as long as in itself a legal action and a criminal action are not at all different from each other since at their core lies the ability to understand.

We are of the opinion that the moment has come to provide for a new coercive measure in the Criminal Code, in addition to compulsory outpatient treatment and compulsory treatment in a medical institution, that of psychosocial type of care. As has resulted from the practice of other countries, the provision of this measure would be particularly effective in treating those subjects who have committed a criminal offense under the conditions of inebriation or use of narcotic and psychotropic substances. Currently, these subjects, who commit a criminal offense in conditions of inebriation or use of narcotic and psychotropic substances, cannot be subject to any kind of rehabilitative measures, but only sentenced to imprisonment. These vulnerable persons manifest mental disorders during the execution of the crime, precisely because of the lack of specialized treatment.

A problem that is often encountered in practice is related to article 48 (b) of the Criminal Code, that of instantaneous profound psychiatric distress. This circumstance is known by other codifications as an emotional or passionate state. The difficulty in the application in practice of this article lies in the lack of unified case law in terms of ascertaining profound psychiatric 
distress. Different courts act in different ways; some of them are satisfied only with the criminal circumstances to assess whether the criminal offense was committed in conditions of profound psychiatric distress, mainly regarding murder and injury, while other courts seek the help of an expert. Referring to the above, we recommend the involvement of the expert in identifying the profound psychiatric distress so as not to leave room for different discussions and attitudes.

Another problem lies precisely in a legal-procedural provision which does not correspond to any provision of the substantive law. Article 192 of the Albanian Code of Criminal Procedure gives the court the legal right to accept documents related to the personality of the defendant in relation to his behavior. This is an ambiguous situation because the emotional and passionate state of the personality of the defendant is not provided for in Albanian law as mitigating circumstances, which are the subject of this manuscript. On the other hand the court can obtain documents related to these conditions even though there is no legal provision. We find it difficult to reach a conclusion as to the intention of the legislature by including the emotional and passionate state only in the provisions of a procedural nature, taking into account the purpose for application of these documents in the absence of relevant provisions. 


\section{References}

Antolisei, F. (1991). Manuale di diritto penale, parte generale [Manual of Criminal Law, general part] (12th ed.). Milano, Italy: Giuffre Editore.

Delpino, L. (2010). Diritto Penale, parte generale [Criminal Law, general part] (2nd ed.). Italy: Edizione Giuridiche Simone.

Elezi, I. (2014). E drejta penale, pjesa e posacme [Criminal Law, special part]. Tirana, Albania: Botimet Kumi.

Elezi, I., Kacupi, S., \& Haxhia, M. (2007). Komentar $i$ Kodit Penal te Republikes se Shqiperise [Commentary of the Criminal Law of the Republic of Albania]. Tirana, Albania: Botimet Kumi.

Faulk, M. (1988). Basic forensic psychiatry. Worcester, Great Britain: Blackwell Scientific Publications.

Fiandaca, G., \& Musco, E. (2014). Diritto Penale, parte generale [Criminal Law, general part] (7th ed.). Bologna, Italy: Zanichelli Editore SpA.

Finkel, N. J. (1988). Insanity on trial. New York, USA: Plenum Press.

Fornari, U. (1997). Trattato di psichiatria forense [Treatise on forensic psychiatry]. Torino, Italy: Utet Giuridica.

General Prosecution Office v. Zyka, 45 (Constitutional Court of the Republic of Albania July 23, 2012). Retrieved June 7, 2021, from http://www.gjk.gov.al/web/Lista_e_Vendimeve_92_1.php

Hoxha, D., Kacupi, S., \& Haxhia, M. (2018). E drejta penale, pjesa e pergjithshme [Criminal Law, general part]. Durres, Albania: Botimet Jozef.

Kambovski, V. (2010). E drejta penale, pjesa e pergjithshme [Criminal Law, general part]. (A. Osmani, \& I. Zeneli, Trans.) Shkup, Macedonia: Furkan.

Mantovani, F. (2001). Diritto penale, parte generale [Criminal Law, general part]. Padova: CEDAM.

Marinuci, G., \& Dolcini, E. (2006). Codice penale commentato [Criminal Code, commented] (2nd ed.). Vincenza, Italy: IPSOA.

Marinuci, G., \& Dolcini, E. (2012). Manuale di diritto penale, parte generale [Manual of Criminal Law, general part] (4th ed.). Milano, Italy: Giuffre Editore SpA.

Muci, S. (2007). E drejta penale, pjesa e pergjithshme [Criminal Law, general part]. Tirana, Albania: Botimet Dudaj.

Perkins, R. M. (1934). Partial insanity. Journal of Criminal Law and Criminology, 25(2). Retrieved June 2, 2021, from https://scholarlycommons.law.northwestern.edu/cgi/viewcontent.cgi? article $=2469 \&$ context $=$ jclc

Petroviq, B. (2006). E drejta penale [Criminal Law]. Prishtina: Universiteti AAB Prishtina.

Prosecution Office Durres v. Gjoka , 171 (Supreme Court of Albania July 14, 2014). Retrieved June 10, 2021, from http://www.gjykataelarte.gov.al/web/Viti_2014_1976_1.php 
Prosecution Office Fier v. Shehaj, 210 (Supreme Court of Albania November 5, 2014). Retrieved June 5, 2021, from

http://www.gjykataelarte.gov.al/web/Viti_2014_1976_1.php

Prosecution Office Fier v. Xhulaj, 202 (Supreme Court of Albania November 2, 2016). Retrieved June 6, 2021, from http://www.gjykataelarte.gov.al/web/Viti_2016_3496_1.php

Prosecution Office Korce v. Adri , 90 (Supreme Court of Albania March 13, 2013). Retrieved June 5, 2021, from http://www.gjykataelarte.gov.al/web/Viti_2013_1575_1.php

Prosecution Office Korce v. Gora \& Shehu , 91 (Supreme Court of Albania June 21, 2017). Retrieved June 10, 2021, from http://www.gjykataelarte.gov.al/web/Viti_2017_4617_1.php

Prosecution Office Kukes v. Kerxhalliu, 152 (Supreme Court of Albania September 30, 2015). Retrieved June 10, 2021, from http://www.gjykataelarte.gov.al/web/Viti_2015_2813_1.php

Prosecution Office Pogradec v. Piperi , 129 (Supreme Court of Albania April 17, 2013). Retrieved June 3, 2021, from http://www.gjykataelarte.gov.al/web/Viti_2014_1976_1.php

Prosecution Office Shkoder v. Leci , 29 (Supreme Court of Albania February 9, 2011). Retrieved June 10, 2021, from http://www.gjykataelarte.gov.al/web/Vendime_Viti_2011_693_1.php Prosecution Office Shkoder v. Ramja, 145 (Supreme Court of Albania November 9, 2011). Retrieved June 7, 2021, from http://www.gjykataelarte.gov.al/web/Vendime_Viti_2011_693_1.php

Prosecution Office Shkoder v. Terolli, 12 (Supreme Court of Albania February 8, 2017). Retrieved June 5, 2021, from http://www.gjykataelarte.gov.al/web/Viti_2017_4617_1.php

Prosecution Office Tirana v. Abazi \& Citaku, 140 (Supreme Court of Albania Septemper 16, 2015). Retrieved June 5, 2021, from http://www.gjykataelarte.gov.al/web/Viti_2015_2813_1.php

Prosecution Office Tirana v. Lataj , 77 (Supreme Court of Albania May 31, 2017). Retrieved June 10, 2021, from http://www.gjykataelarte.gov.al/web/Viti_2017_4617_1.php

Prosecution Office Tirana v. Qiqi , 4 (Supreme Court of Albania April 15, 2014). Retrieved June 6, 2021, from http://www.gjykataelarte.gov.al/web/Viti_2014_1976_1.php

Prosecution Office Tropoja v. Osmanaj , 7 (Supreme Court of Albania February 14, 2018). Retrieved June 10, 2021, from http://www.gjykataelarte.gov.al/web/Viti_2018_5188_1.php

Prosecution Office Tropoja v. Ukcamaj , 16 (Supreme Court of Albania January 26, 2011). Retrieved June 6, 2021, from http://www.gjykataelarte.gov.al/web/Vendime_Viti_2011_693_1.php

Prosecution Office Vlore v. Vasili (Saliaj), 129 (Supreme Court of Albania June 29, 2016). Retrieved June 7, 2021, from http://www.gjykataelarte.gov.al/web/Viti_2016_3496_1.php 
Salihu, I. (2010). E drejta penale, pjesa e pergjithshme [Criminal Law, general part]. Prishtina: Universiteti FAMA.

Shtino, N. (2003). Psikiatria ligjore [Forensic psychiatry]. Tirana, Albania: Botimet Toena.

Shtino, N., \& Lala, S. H. (2011). Psikiatria ligjore [Forensic psychiatry]. Tirana, Albania: Albtipografia.

Strazimiri v. Albania, 34602/16 (Europian Court of Human Rights January 21, 2010). Retrieved June 12, 2021, from https://laweuro.com/?p=10619

Vehbiu, U., \& Shtino, N. (1986). Psikiatria ligjore [Forensic psychiatry]. Tirana, Albania: Shtypshkronja Dispensa.

Zappa, G., \& Alberto, R. C. (n.d.). Infermita mentale, pericolosita sociale e misure di sicurezza alla prova degli anni duemila [Insanity, social danger and safety measures put to the test of the 2000s]. Retrieved June 11, 2021, from http://www.rassegnapenitenziaria.it/cop/22146.pdf 